\title{
Vascular Supply to the Lumbar Spine: An Intimate Look at the Lumbosacral Nerve Roots
}

\author{
Russell V. Gilchrist, MD *, Curtis W. Slipman, MD**, Zacharia Isaac, MD\#, David A. Lenrow, MD\#\# \\ and Larry H. Chou, MD*
}

The vascular supply of the lumbar vertebral column is a diverse collection of arteries originating from both central and peripheral sites. Until recently, the majority of these studies have been dedicated to the blood supply of the spinal cord and vertebral bodies. More recent effort has been directed toward the identification of the vascular supply to the lumbar nerve roots. These studies have conclusively documented the presence of a dual blood supply to the nerve roots. In addition, this dual vascular supply has been discovered to have the capability for bidirectional flow. This unique property may allow for prevention of localized, compressive ischemic symptoms secondary to either herniated disc material or osteophytes. The nutrient contributions of the cerebrospinal fluid and venous supply to nerve roots have also been investigated. Early studies indicate that they may play a greater role than suspected. The presence of multiple sources of nutrient supply to the lumbar nerve roots enables them to be resistant to the potential compressive phenomenon that may occur in the lumbar spine.

Keywords: anatomy, spine, lumbar nerve root, vascular supply

then, a number of anatomic studies have definitively identified the vascular supply of the lumbar nerve roots (4-8). This article will consolidate the anatomic knowledge gleaned to date involving the vascular supply of the lumbar nerve roots. A brief overview of the vascular supply to the lumbar spine will be presented to allow the reader a more comprehensive understanding of the complex nature of arterial and venous vascular patterns.

\section{VASCULAR SUPPLY OF LUMBAR SPINE} tention to the arterial supply of the nerve roots was first brought into the forefront by Verbiest et al (3) in 1954. His landmark article examined lumbar spinal stenosis as a cause for intermittent claudication of the lumbar nerve roots resulting in lower extremity pain symptoms. Since

From Hospital of the University of Pennsylvania, Philadelphia, Pennsylvania. *Dr. Gilchrist is a fellow, **Dr. Slipman is a director of the Penn Spine Center, associate professor, \#Dr. Isaac is a fellow, \#"Dr. Lenrow is assistant professor of the Department of Rehabilitation Medicine and Dr. Chou is director of Physical Medicine \& Rehabilitation Services at Penn Medicine at Radnor and assistant professor of the Department of Rehabilitation Medicine at Hospital of the University of Pennsylvania. Address correspondence: Curtis W. Slipman, MD, 3400 Spruce Street, Philadelphia, PA 19104. E-mail: slipman@mail.med.upenn.edu
In the lumbar region there are four paired lumbar arteries that arise from the posterior wall of the abdominal aorta. They provide blood supply to the first four lumbar vertebral bodies. These vessels pass laterally on each side remaining closely applied to the center of the anterior and sides of the vertebral bodies until they reach the intervertebral foramina. The fifth lumbar segment is supplied by small branching vessels from the middle sacral artery and branches from the iliolumbar arteries $(4,9)$. Like the upper lumbar arteries, the middle sacral artery also arises from the posterior wall of the abdominal aorta.

Each lumbar artery gives off two sets of branches in relation to the vertebral body. The first branch of the lumbar artery is the short centrum branch (10). They penetrate the vascular foramina at regular intervals, subjacent to the lumbar artery. The second set of vessels 
are the longer ascending and descending branches that form dense networks along the anterior and lateral aspects of the vertebral bodies. Their terminal branches enter the bone in the area adjacent to each vertebral end plate, while other branches form fine vertical networks on the surfaces of the anterior longitudinal ligament and annulus fibrosis (11). The small segmental arteries subserving the fifth lumbar vertebra, sacrum, and coccyx are of variable caliber originating from the back of the aorta just above its bifurcation and ending at the coccygeal body.

At the level of the intervertebral foramina, but immediately lateral to the exit zone, each lumbar artery divides into a series of major branches. These include the anterior, intermediate, and posterior branches (11). The anterior branches lie medial to and then behind the psoas muscles anterior to the lumbar plexus. Neural branches from the dorsal rami descend with each anterior segment of the lumbar nerve (12).

The intermediate branch of the lumbar artery divides into three subdivisions: the anterior spinal branches, nervous system branches, and posterior spinal branches. The anterior spinal canal branch bifurcates into an ascending and descending branch immediately after entering the spinal canal. They anastomose with corresponding ascending and descending branches from above and below to form a dense network of vessels on the anterior wall of the spinal canal. The nervous branches from the intermediate artery travel both proximal and distally with nerves within the canal. The posterior branches of the intermediate artery form a closely woven network on the anterior surface of the lamina and ligamentum flavum giving them blood supply. A laminar branch also arises from the posterior spinal canal arterial network on each side. This laminar branch enters the lamina and courses toward the facet joints giving blood supply to both (11).

The posterior branches of the lumbar artery pass backwards away from the foramina to lie on the outer surface of the lamina and cross each pars interarticularis. As these arteries pass the zygapophyseal joints they give branches to supply the posterior aspects of this joint (11). They continue to travel posteriorly lying along the middle surface of each spinous process. They give ascending and descending branches at this point to supply the paraspinal muscles, and penetrating branches to give blood supply to the spinous processes (11).

Direct branches off the lumbar arteries supply the internal aspect of the vertebral body, the corresponding superior and inferior end plates anteriorly, and posteriorly by branches from the anterior division of the lumbar artery. These vessels penetrate the vertebral body in a horizontal plane to form a dense arterial complex. From this complex they send vertical branches superiorly and inferiorly to supply the vertebral body and end plate (11).

The vascular pattern for venous drainage closely resembles its arterial supply (13). In the vertebral body there are two main venous collection systems. The main vertebral body contains a horizontal articular collecting system, which receives drainage from the majority of the interior vertebral body (14). The peripheral aspects of the vertebral body drain directly into either the anterior internal or external vertebral venous plexus. A second venous drainage network is seen at the level of the vertebral end plate. This network is termed the subchondral postcapillary venous network of the vertebral bodies. It is smaller and runs a relatively horizontal and parallel course to the subarticular collecting vein system. This postcapillary network drains into adjacent veins on the surface of the vertebral bodies or sends tributaries to the articular collecting system $(15,16)$. From these two internal networks, venules drain into a large venous grid from which the basivertebral veins arise (13). The basivertebral vein then proceeds posteriorly to merge with the anterior internal vertebral plexus. This anterior internal plexus runs along the anterior and posterior walls of the spinal canal. It joins with the external venous plexus at lumbar intervertebral foramen to form lumbar veins. These lumbar veins are connected on the anterolateral surface of the vertebral bodies by a network of veins called the external vertebral venous plexus (11). The lumbar veins then drain into the vena cava and left common iliac vein. Posterior elements of the lumbar vertebral canal receive venous drainage from vessels traveling in a similar distribution to the posterior arterial branches of the lumbar artery. They empty into the lumbar vein at the level of the intervertebral foramen (15). The lumbar veins then end their course by emptying into the inferior vena cava.

\section{ANATOMY OF THE NERVE ROOT}

Before discussing the vascular supply of the lumbosacral roots we will briefly review some pertinent anatomical aspects that differentiate nerve roots from peripheral nerves. As each nerve root exits the spinal cord it maintains a connection with the thecal sac by carrying with it an outer sleeve containing the dura mater, arachnoid mater, and nerve root sheath (17). It was not until the midtwentieth century that this root sleeve was identified. 
Previous studies continued to report the presence of endoand perineurium overlying the nerve root $(18,19)$. Gamble et al (20) in 1964 published the first study to identify the replacement of the endoneurial sheath with a "pial sheath". He also demonstrated the absence of an epineural sheath overlying the nerve root. He identified the dural sac as the continuation of the epineurium proximally (20). This connection to the thecal sac allows cerebrospinal fluid (CSF) to course along the length of the nerve roots (21). A number of studies have demonstrated the arachnoid and nerve root sheath lining to have a gauze-like architecture that allows the CSF to flow into and around the endoneurium $(22,23)$. The presence of CSF gives the nerve root an added supply of nutrients supplementing the normal vascular supply. Some studies have reported that as much as 50-70\% of the nerve roots metabolic needs may be provided by the $\operatorname{CSF}(22,23)$. Fibrosis of the arachnoid-root sheath complex can result in decreased diffusion capacity of CSF thereby resulting in arachnoiditis-like symptoms.

The nerve root sleeve terminates at the joining of ventral and dorsal roots to form the foraminally located spinal nerve. In contrast, the spinal nerves and their subsequent peripheral nerve branches contain an outer lining consisting of epineurium and perineurium (17). This outer lining of the peripheral nerve contains an increased collagen content that gives it stronger resistance to injury. In comparison, the nerve root dural-arachnoid-sheath lining contains less collagen fibers thereby making it less apt to protect the nerve root from compressive or traction forces $(20,24)$. Ligaments binding to the dural sleeve serve to fix the nerve root to surrounding spinal canal structures (25). These ligaments may potentially cause tethering of nerve roots resulting in ischemia and subsequent pain production (25).

\section{VASCULAR SUPPLY OF THE NERVE ROOT}

Blood supply to the lumbar spinal nerve roots occurs proximally from branches of the longitudinal vessels of the conus medullaris. These vessels only travel a few centimeters along the rootlets before terminating (8). The posterior (or dorsal) nerve roots receive their vascular supply via the dorsolateral longitudinal spinal arterial system. This system is an extension of the vasa corona that forms a plexiform, interrupted network of vessels that is always in close proximity to the posterior rootlets. The ventral roots each receive a direct branch from the nearest vasa corona (8).
The remaining proximal portions of the nerve roots receive blood supply via the dorsal and ventral proximal radicular arteries (15). These blood vessels are derived from the dorsal longitudinal spinal artery and accessory anterolateral artery, respectively. The proximal radicular arteries enter the nerve root and follow the length of the nerve distally to anastomose with the distal radicular artery (15). Their entrance into the proximal nerve roots occurs slightly distal to the roots exit from the spinal cord. This delay in contact is most likely due to proximal regions of the nerve root already receiving vascular supply from the dorsal and anterior longitudinal vessels. As the proximal radicular artery enters the nerve root it follows along with one of the main fascicular bundles. A number of collateral branches occur directly off of the main radicular artery. These smaller branches tend to form parallel courses along other nerve root fascicles (8). Precapillary branching from these long running parallel vessels give supply to the subdivisions of fiber bundles not directly overlying the radicular arteries. These branches are unique in that they are coiled shaped. Coiling of these precapillary vessels has been noted to endow these vessels with a resistance to compression during flexion and extension moments of the spine, thereby preventing ischemia to nerve root fascicles (8).

The distal radicular artery branches from the lumbar artery at the level of the intervertebral foramen. It then divides into two branches, one entering each dorsal and ventral root. At this point it travels both proximal and distally along the length of the nerve roots giving it blood supply (7). As the distal radicular artery travels proximally it forms numerous arteriovenous anastomoses with neighboring veins (26).

There are two venous systems involved in drainage of lumbar nerve roots. They are divided into proximal and distal radicular venous systems. The distal radicular veins drain into the lumbar vein at the level of the intervertebral foramen. The proximal radicular veins drain into the spinal cord venous plexuses (7). They have been documented to return via the vasa corona and then pass proximally in the anterior and posterior longitudinal veins of the cord (8). A study has demonstrated that the veins are similar to nerve root arteries in they have a variable location and number in the nerve root (15). The major veins of the nerve root demonstrate closer morphology and arrangement to those of the central nervous system. Their walls are comparatively thin and lack a tunica media. In contrast to peripheral nerves, nerve roots tend to have fewer numbers of veins and tend toward a more spiraling course through 
the deeper portions of the nerve root (8).

\section{NUTRITIONAL SUPPLY OF NERVE ROOT}

As mentioned earlier, the nerve roots are unique in they receive a dual nutrient supply $(22,23)$. The degree of contribution of the CSF was only theorized upon until the work of Rydevik et al (22) in 1984. In their study, they compared the uptake of methyl-H-glucose in pigs by performing concomitant intravenous and subarachnoid injections. They discovered that the CSF contributed $58 \%$ of the isotope, and the radicular vessels gave only $35 \%$ of the labeled isotope (22). This finding stands in stark contrast to the peripheral nerve, which receives $95 \%$ of its nutritional supply from the arterial vessels (8). In a secondary analysis by Rydevik et al (22) sections of lumbar nerve root and sciatic nerve were performed on pigs. A microscopic analysis of capillaries was conducted. Microscopically, the peripheral nerve demonstrated twice the number of capillaries per field as the nerve root. This study lends credence to Rydevik's other work that the CSF contributes a significant portion of the nutrient supply to the nerve root (22). In support of Rydevik's studies is more recent works published study performed by Yoshizawa et al (27). They documented flow of CSF into the subarachnoid space and endoneurium of the nerve root. Interruption of the CSF flow through the pial-root sheath may cause potential ischemia to the nerve root. This interruption most likely would be due to either an acute compressive phenomenon or chronic fibrosis of the pialroot sheath secondary to chronic inflammatory changes (28). In both instances surgical decompression is a possible option for early treatment in the injury process. Nerve root steroid injection may also play a role in preventing the cascade of inflammatory events that result in fibrosis formation. More anatomic studies are needed to investigate the prevalence of fibrosis of the pial-root sheath in patients with chronic low back or leg pain complaints.

\section{DIRECTION OF ARTERIAL FLOW}

Until recently, it was generally accepted that arterial flow through the lumbar nerve roots occurred toward the spinal cord (8). Parke et al (7), in 1981, was one of the first to establish a dual arterial supply of the lumbar nerve roots. A proximal radicular artery gives blood flow in a distal direction from the cord towards the spinal nerve. Concomitantly, a distal radicular artery provided blood flow in a proximal direction toward the cord. An area of hypovascularity was noted in the proximal third of the nerve root. This discovery led the authors to postulate on the possibility of a "watershed area," which could be responsible for the neuroischemic manifestations of compressive phenomenon involving the lumbar nerve root (7). Other later studies were unable to reproduce this area of hypovascularity $(5,28)$. Kobayashi et al (28) in 1989 injected India ink into the aorta of dogs and obtained highspeed serial photographs of surgically exposed lumbar nerve roots. Through the use of serial photography they were able to document cephalad arterial flow in the distal extradural root and caudal flow from the proximal radicular arteries. Compression of proximal arterial flow caused a marked compensatory response from the distal ascending arterial flow. The distal flow was noted to extend beyond its' normal boundaries and give blood supply to the more proximal nerve root segments. In addition, complex, intricate networks of intrinsic arteries were noted throughout the substance of the nerve. The presence of these intrinsic vessels prevents development of a "watershed area" in the proximal third of the nerve root. A more recent study by Kobayashi et al (29) in 2000 examined nerve root circulation using seriography in live dogs. They injected $3 \mathrm{cc}$ of India ink through an aortic catheter to determine direction of blood flow in vessels running along the roots. Once completed, the nerve root was then compressed to evaluate for any compensatory flow adaptations. Finally, $300 \mathrm{~mL}$ of India ink was injected through the aortic catheter and the nerve root vascular structures were observed under a stereoscopic microscope. The dogs were then sacrificed and nerve roots were harvested to undergo Spalteholz technique preparation. The specimens were then analyzed under a stereoscopic microscope (29). After India ink injection there was caudal and cephalad arterial flow observed. The main vessels identified were the proximal and distal radicular arteries. Merging of the two arterial flows was seen to occur at the bundling of the nerve root filaments just lateral to the edge of the spinal cord. A potential watershed area was seen to exist at this site of merging. Clamping of the nerve root near the inlet of the dural sleeve resulted in reversal of normal blood flow. This compensatory response by the proximal radicular artery is probably achieved through the watershed area by of numerous intra-radicular connections. In the case of compression, these arterial connections were seldom seen to be affected (29).

The presence of this dual flow pattern makes compression of the distal radicular artery less likely to be a cause of ischemic spinal stenosis symptoms. In addition, the walls of the radicular arteries are thick and resistive to compression, and the arterial flow is under a high-pressure 
system. These secondary factors aid in maintaining their patency and preventing ischemia to the nerve roots.

A more likely cause of impairment in blood flow is disruption of venous flow in the nerve root. The veins of the nerve root have thin walls and are under much lower flow pressures, thereby making them more apt to deformation from compressive forces than their neighboring root arteries $(30,31)$. This impairment in venous flow causes resultant edema of the surrounding nerve root (32). Blood flow through intrinsic vessels and surrounding CSF flow is subsequently arrested due to this edema and ischemia of the nerve root results $(32,33)$.

\section{CONCLUSION}

The vasculature of nerve roots has gone relatively unexplored until the latter half of the twentieth century. Around that time, the diagnosis of lumbar spinal stenosis was postulated leading to an increased focus on the vascular anatomy of the lumbar nerve roots. Since then a number of morphologic studies have been able to establish the presence of a dual arterial blood supply to the nerve roots. More recent studies have shown that compression of proximal or distal radicular vessels is well compensated by flow of the opposing radicular artery. Due to this dual blood supply, ischemic symptoms are unlikely to be caused by compression of one of these arteries. The most popular current theory of ischemic nerve root symptoms is via vasogenic edema of the nerve root created by interruption of venous flow. This edema subsequently prevents flow of CSF, which is responsible for the majority of nutritional supply to the nerve root.

\section{REFERENCES}

1. Adamkiewicz A. Die Blutggefasse des menschlichen Ruckenmarkes: I. Die Geffase der Ruckenmarkssubstanz. Sitzungsber. Akad.d. Wiss. In Wein. Math-naturwiss. K1 Press, 1881, pp 469-502.

2. Kadyi H. Uber die Blutgefasse des Menchlichen Ruckenmarkes. Anat Anz 1886; 1:304-314.

3. Verbiest H. A radicular syndrome from developmental narrowing of the lumbar vertebral canal. J Bone Joint Surg (Br) 1954; 36:230-237.

4. Crock HV, Yoshizawa H. The blood supply of the vertebral column and spinal cord in man. SpringerVerlag, New York: 1977.

5. Crock HV, Yamagishi M, Crock MC. The conus medullaris and cauda equina in man. SpringerVerlag, New York, 1986.

6. Parke WW. The significance of impaired venous return in ischemic radiculopathy and myelopathy.
Orthop Clin North Am 1991; 22:213-221.

7. Parke WW, Gammell K, Rothman RH. Arterial vascularization of the cauda equina. J Bone Joint Surg (Am) 1981; 63:53-62.

8. Parke WW, Watanabe R. The Intrinsic vasculature of the lumbosacral spinal nerve roots. Spine 1985; 10:508-515.

9. Kauppila LI. Prevalence of stenotic changes in arteries supplying the lumbar spine. A postmortem angiographic study on 140 subjects. Annu Rheum Dis 1997; 56:591-595.

10. Crock HV, Yoshizawa H. The blood supply of the lower limb bones in man. Edinburgh, E and S, Livingston, New York, 1967.

11. Crock HV, Yoshizawa H. The blood supply of the lumbar vertebral column. Clin Orthop 1976; 115:621.

12. Bogduk N, Wilson AS, Tynan W. The human lumbar dorsal rami. J Anat 1982; 134:383-397.

13. Dupuis PR. The Anatomy of the Lumbosacral Spine. In Kirkaldy-Willis WH, Burton CV. Managing Low Back Pain. Churchill Livingstone, New York, 1992, pp 7-35.

14. Crock HV, Goldwasser M. Anatomic studies of the circulation in the region of the vertebral end-plate in adult greyhound dogs. Spine 1984; 9:702-706.

15. Dommisse GF, Grobler L. Arteries and veins of the lumbar nerve roots and cauda equina. Clin Orthop 1976; 115:22-29.

16. Macintosh JE, Bogduk N. The morphology of the lumbar erector spinae. Spine 1986; 12: 658-668.

17. Yoshizawa H, Kobayashi S, Hachiya Y. Blood Supply of Nerve Roots and Doral Root Ganglia. Orthop Clin North Am 1991; 22:195-211.

18. Laidlaw G. Silver staining of the endoneurial fibers of the cerebrospinal nerves. Am J Pathol 1930; 6:435444.

19. Tarlov IM. Structure of nerve roots. Arch Neurol Psychiat 1937; 37:555-853.

20. Gamble HJ. Comparative electron microscopic observations on the connective tissues of a peripheral nerve and a spinal nerve root in the rat. J Anat 1964; 98:17-25.

21. Bogduk N. Blood supply of the lumbar spine. In Clinical Anatomy of the Lumbar Spine and Sacrum. Churchill Livingstone, New York, 1997, pp 145-153.

22. Rydevik B, Holm S, Brown. Nutrition of the spinal nerve roots: The role of diffusion from the CSF. In Transactions of the $30^{\text {th }}$ Annual Meeting of the Orthopaedic Research Society 1984; Feb 7-9: 276.

23. Rennels ML, Gregory TF, Blaumanis OR, et al. Evidence for a perivascular fluid circulation in the mammalian central nervous system provided by the rapid distribution of a tracer protein throughout the brain from the subarachnoid space. Brain Res 1985; 326:47-63. 
24. Stodieck LS, Beel JA, Luttges MW. Structural properties of spinal nerve roots: Protein composition. Exp Neurol 1986; 91:41-51.

25. Spencer DL, Irwin GS, Miller JAA. Anatomy and significance of fixation of the lumbosacral nerve roots in sciatica. Spine 1983; 8:672-679.

26. Yamamoto H. Quantitative measurements of blood flow in cauda equina and spinal cords of monkeys using radioactive microspheres. Journal Japanese College of Angiology 1982; 22:35-42.

27. Yoshizawa H, Kobayashi S, Kubota K. Effects of compression on intra-radicular blood flow in dogs. Spine 1989; 14:1220-1225.

28. Kobayashi S, Yoshizawa H, Nakai S. Experimental study on the blood supply of the lumbar nerve root in dog. Cent Jpn Orthop Traumatol 1989; 31:133-135.

29. Kobayashi S, Yoshizawa H, Nakai S. Experimental study on the dynamics of lumbosacral nerve root circulation. Spine 2000; 25:298-305.

30. Delmarter LB, Bohlman HH, Dodge LD et al. Experimental lumbar spinal stenosis. J Bone Joint Surg (Am) 1990; 72:110-120.

31. Olmarker K, Rydevik B, Holm S. Edema formation in spinal nerve roots induced by experimental graded compression. Spine 1989; 14:569-573.

32. Kobayashi S, Yoshizawa H, Hachiya Y et al. Vasogenic edema induced by compression injury to the spinal nerve root. Spine 1993; 18:1410-1424.

33. Olmarker K, Rydevik B, Holm S. Edema formation in spinal nerve roots induced by experimental, graded compression: An experimental study on the pig cauda equina with special reference to differences in effects between rapid and slow onset of compression. Spine $1989 ; 14: 569-573$. 